\title{
Reabilitação térmica: Contributo das argamassas com incorporação de material de mudança de fase
}

\author{
Thermal rehabilitation: Contribution of \\ mortars with incorporation of phase \\ change materials
}

\author{
Sandra Cunha ${ }^{1}$, José Aguiar ${ }^{1}$, \\ Victor Ferreira ${ }^{2}$, António Tadeu ${ }^{3}$
}

\footnotetext{
${ }^{1}$ Universidade do Minho, Campus de Azurém, CEP: 4800-058, Guimarães, Braga, Portugal.

${ }^{2}$ Universidade de Aveiro, Campus Universitário de Santiago, CEP: 3810-193, Aveiro, Distrito de Aveiro, Portugal.

${ }^{3}$ Universidade de Coimbra, Rua Luís Reis Santos - Pólo II da Universidade, CEP:3030-788, Coimbra, Distrito de Coimbra, Portugal.

e-mail: sandracunha86@gmail.com, aguiar@civil.uminho.pt, victorf@ua.pt, tadeu@dec.uc.pt
}

\begin{abstract}
RESUMO
O setor residencial encontra-se muitas vezes envelhecido, apresentando necessidades de intervenções urgentes. Assim, torna-se importante reabilitar edifícios do ponto de vista estrutural, estético e funcional. A reabilitação térmica é uma importante oportunidade para atingir níveis mais elevados de desempenho energético, reduzindo a elevada dependência energética dos países. As operações de reabilitação baseadas na utilização de materiais com capacidade de armazenamento e liberação de energia contribuem para a obtenção de edifícios mais eficientes em termos energéticos. Combinando a utilização de materiais inteligentes e fontes de energia renováveis, é possível aumentar o conforto térmico dentro dos edifícios. O principal objetivo deste trabalho consistiu na caracterização física, mecânica e térmica de argamassas baseadas em ligantes específicos para reabilitação, com incorporação de materiais de mudança de fase (PCM). Foram estudadas argamassas à base de cal aérea e gesso, sendo que, para cada ligante, foram desenvolvidas argamassas com e sem incorporação de PCM. Observou-se que a incorporação de PCM nas argamassas originou diferenças no seu comportamento físico, mecânico e térmico. Verificou-se uma diminuição das resistências à flexão e compressão, assim como uma melhorado comportamento térmico, reduzindo a temperatura máxima, aumentando a temperatura mínima e diminuindo as necessidades de aquecimento e arrefecimento.
\end{abstract}

Palavras-chave: Argamassas, Materiais de mudança de fase, Reabilitação térmica.

\begin{abstract}
The residential sector is sometimes old, with urgent intervention needs. Thus, it is important to rehabilitate buildings from a structural, aesthetic and functional point of view. The thermal rehabilitation is an important opportunity to reach higher levels of energetic performance, reducing the high energetic dependence of the countries. Rehabilitation operations based in the utilization of materials with the capability to store and release energy contribute to obtain more energy efficient buildings. Combining the use of smart materials and renewable energy sources, it is possible to increase the thermal comfort inside the buildings. The main purpose of this study was the physical, mechanical and thermal characterization of mortars based in specific binders for rehabilitation with incorporation of phase change materials (PCM). Mortars based in aerial lime and gypsum were studied. For each binder, mortars with and without incorporation of PCM were developed. It was observed that the incorporation of PCM in mortars caused differences in the physical, mechanical and thermal behavior. It was verified a decrease in the flexural and compressive strengths, and an increase in the thermal behavior, reducing the maximum temperature, increasing the minimum temperature and decreasing the heating and cooling needs.
\end{abstract}

Keywords: Mortars, Phase change materials, Thermal rehabilitation. 


\section{INTRODUÇÃO}

Geralmente, em operações de reabilitação em edifícios, existe a necessidade de substituir as argamassas aplicadas. Desta forma, verifica-se a possibilidade de utilizar argamassas avançadas, com funções específicas, tais como: argamassas retardadoras de fogo [1], argamassas com capacidade de auto-limpeza [2], argamassas com capacidade de purificação do ar $[3,4]$ e argamassas com capacidade de armazenamento térmico [5, 6, $7,8]$.

Atualmente, em alguns países o setor residencial encontra-se bastante envelhecido. Uma parte significativa dos edifícios não apresenta níveis adequados de eficiência energética, necessitando de intervenções urgentes para melhorar as suas condições térmicas. A principal razão deste problema, deve-se ao facto destes edifícios terem sido construídos antes da existência de qualquer legislação para a regulamentação dos projectos térmicos. Assim, a maior parte dos edifícios apresenta baixa qualidade energética, devido fundamentalmente ao fraco isolamento aplicado ou até à inexistência do mesmo.

Em todo o mundo, as principais fontes de energia utilizadas são os combustíveis fósseis, tais como o carvão, o petróleo e o gás natural, que originam elevadas emissões de dióxido de carbono e impactos negativos para o meio ambiente [9]. Na Europa, o sector da construção é responsável por cerca de 40\% do consumo de energia [10]. Assim, atualmente as preocupações relacionadas com o consumo de energia dos edifícios são cada vez maiores, uma vez que a energia e a segurança ambiental são os principais problemas da economia global.

A reabilitação de edifícios constitui uma boa oportunidade para atingir níveis mais elevados de desempenho, reduzindo o consumo energético e as emissões de $\mathrm{CO}_{2}$ para o ambiente [11]. Assim, a reabilitação térmica e energética dos edifícios é um meio importante para a correcção de situações funcionais inadequadas, proporcionando uma melhoria da qualidade térmica e das condições de conforto dos ocupantes, reduzindo o consumo de energia associada ao aquecimento e arrefecimento.

Uma possibilidade para a reabilitação térmica dos edifícios consiste na utilização de materiais de construção com incorporação de materiais de mudança de fase (PCM). A utilização de PCM permite a regulação da temperatura no interior dos edifícios, através do armazenamento térmico de energia latente, utilizando apenas a energia solar como recurso. O princípio de funcionamento do PCM consiste na capacidade de absorver e armazenar energia térmica, quando a temperatura ambiente aumenta até o ponto de fusão do material. Neste caso, o material sofre uma alteração do estado sólido para o estado líquido. Por outro lado, quando a temperatura ambiente diminui até o ponto de solidificação do PCM, o material altera novamente o seu estado, neste caso do estado líquido para o estado sólido, liberando a energia anteriormente armazenada, novamente para o ambiente.

Nos últimos anos, foram publicados diversos estudos relacionados com materiais de construção com incorporação de PCM. As placas de gesso com incorporação de PCM têm sido alvo de vários estudos, devido ao seu baixo custo e às variadas possibilidades de aplicação [6, 7, 8, 12]. Darkwa et al. [6], investigaram o comportamento de duas soluções com incorporação de PCM. Por um lado, utilizaram placas de gesso cartonado, com $12 \mathrm{~mm}$ de espessura, impregnadas com PCM de modo a comparar diretamente com uma outra situação, em que aplicaram placas de gesso cartonado simples, com $10 \mathrm{~mm}$ de espessura, revestidas por lâminas de PCM com $2 \mathrm{~mm}$. A quantidade de PCM incorporada em ambos os casos foi de 17\%. Os resultados demonstraram que a utilização de PCM laminado foi mais eficiente uma vez que contribuiu para um aumento de $17 \%$ na temperatura interior mínima. Outras soluções foram desenvolvidas tais como painéis de PVC alveolar com PCM macroencapsulado, blocos, tijolos e argamassas [13, 14, 15, 16, 17]. Cabeza et al. [14] construíram e monitoraram o comportamento de células de teste em betão, com e sem incorporação de 5\% em massa de microcápsulas de PCM. O betão com incorporação de PCM foi utilizado na cobertura e nas paredes Sul e Oeste. Durante o verão, foram registrados $3^{\circ} \mathrm{C}$ de diferença na temperatura superficial máxima, com um desfasamento temporal de cerca de 2 horas.

As argamassas com incorporação de microcápsulas de PCM têm sido alvo de estudo e interesse por parte da comunidade científica. No entanto, a caracterização e comparação de argamassas térmicas baseadas em diferentes ligantes e especialmente desenvolvidas para a reabilitação de edifícios é ainda uma área não desenvolvida. As argamassas utilizadas nas obras de reabilitação devem ser baseadas nos mesmos ligantesque as argamassas existentes. Assim, neste estudo foram desenvolvidas quatro composições distintas à base de cal aérea e de gesso com incorporação de $40 \%$ de microcápsulas de PCM e sem incorporação de PCM. Foram realizados vários ensaios para avaliar as principais propriedades físicas, mecânicas e térmicas.

\section{MATERIAIS E MÉTODOS}




\subsection{Materiais}

Foram desenvolvidas argamassas à base de cal aérea e gesso para a reabilitação de revestimentos interiores em edifícios, com comportamento térmico melhorado. A cal aérea utilizada possui uma pureza de $90 \%$ e uma densidade de $2450 \mathrm{~kg} / \mathrm{m}^{3}$. O gesso utilizado possui elevada finura e uma densidade de $2740 \mathrm{~kg} / \mathrm{m}^{3}$. As fibras utilizadas são sintéticas de poliamida com um comprimento de $6 \mathrm{~mm}$, uma espessura de $22.3 \mu \mathrm{m}$ e uma densidade de $1380 \mathrm{~kg} / \mathrm{m}^{3}$. O superplastificante utilizado é à base de poliacrilato, com uma densidade de 1050 $\mathrm{kg} / \mathrm{m}^{3}$. Finalmente, a areia utilizada possui uma densidade de $2600 \mathrm{~kg} / \mathrm{m}^{3}$. Com base na distribuição granulométrica foram obtidos os parâmetros D10, D50 e D90, sendo que estes correspondem a $0.15 \mathrm{~mm}, 0.31 \mathrm{~mm}$ e a $0.48 \mathrm{~mm}$, respectivamente.

As microcápsulas de PCM utilizadas são comercializadas pela Devan Chemicals, com o nome comercial de Mikathermic D24. O material é composto por uma parede em melamina-formaldeído e por um núcleo em parafina, com uma temperatura de transição de cerca de $22.5^{\circ} \mathrm{C}$, entalpia de $147.9 \mathrm{~kJ} / \mathrm{kg}$ e densidade de $880 \mathrm{~kg} / \mathrm{m}^{3}$. O processo de fabrico das microcápsulas de PCM é policondensação por adição. Este material apresenta uma temperatura de transição de $24^{\circ} \mathrm{C}$ no ciclo de aquecimento e de $21^{\circ} \mathrm{C}$ no ciclo de arrefecimento. As dimensões das microcápsulas de PCM foram avaliadas utilizando um granulômetro laser. Foi possível observar uma distribuição de partículas compreendida entre 5.8 e $339 \mu \mathrm{m}$, com cerca de $80 \%$ do tamanho de partícula entre 10.4 e $55.2 \mu \mathrm{m}$ e um tamanho médio de partícula de $44 \mu \mathrm{m}$.

\subsection{Composições}

Foram desenvolvidas quatro composições, tendo em consideração a futura aplicação das argamassas em operações de reabilitação em edifícios (Tabela 1). Os ligantes utilizados foram a cal aérea e o gesso. Para cada ligante foram desenvolvidas argamassas de referência (0\% PCM ) e argamassas com incorporação de $40 \%$ de PCM.

Tabela 1: Composição das argamassas $\left(\mathrm{kg} / \mathrm{m}^{3}\right)$.

\begin{tabular}{l|l|l|l|l|l|l|l}
\hline COMPOSIÇÃO & LIGANTE & AREIA & PCM & SUPERPLASTIFICANTE & FIBRAS & ÁGUA \\
\hline CA500-0PCM & Cal Aérea & 500 & 1447.2 & 0 & 15 & 0 & 225 \\
\hline CA800-40PCM-F & Cal Aérea & 800 & 425.2 & 170.1 & 24 & 8 & 288 \\
\hline G500-0PCM & Gesso & 500 & 1360.4 & 0 & 15 & 0 & 280 \\
\hline G500-40PCM-F & Gesso & 500 & 535.8 & 214.3 & 15 & 5 & 350 \\
\hline
\end{tabular}

\subsection{Procedimentos experimentais}

Para a caracterização física e mecânica das argamassas, foram preparados três provetes prismáticos, com dimensões de $40 \times 40 \times 160 \mathrm{~mm}^{3}$, de acordo com a norma EN 1015-11 [18]. Após a sua preparação, todos os provetes foram armazenados durante 7 dias em sacos de polietileno e posteriormente colocados em laboratório à temperatura ambiente de $22^{\circ} \mathrm{C}$ durante 21 dias.

A quantidade de água de amassadura de cada argamassa foi determinada de forma a conferir uma trabalhabilidade adequada, tendo sido realizada com base no método da mesa de espalhamento, especificado pela norma europeia EN 1015-3 [19]. O valor resultante do ensaio apenas foi considerado, quando compreendido entre 200-220 mm.

O comportamento mecânico foi avaliado com base na resistência à flexão e compressão, de acordo com a norma europeia EN 1015-11 [18]. Os ensaios de determinação da resistência à flexão e compressão realizaram-se com controle de força a uma velocidade de $50 \mathrm{~N} / \mathrm{s}$ e $150 \mathrm{~N} / \mathrm{s}$, respectivamente.

O ensaio para determinação da absorção de água por capilaridade foi efetuado com base na norma europeia EN 1015-18 [20]. Os elementos de ensaio foram obtidos por corte, através dos ensaios de flexão de 3 provetes prismáticos, resultando assim em 6 elementos de ensaio. A água absorvida foi quantificada através da realização de sucessivas pesagens dos provetes. Estas pesagens foram feitas de acordo com um plano previamente estabelecido, com início no primeiro contato dos provetes com a água. Com o objetivo de avaliar a evolução de absorção de água até à sua estabilização, foram realizadas medições periódicas durante 9 dias. As pesagens foram sempre efetuadas depois de removida a água superficial. A determinação da absorção de 
água por imersão foi efetuada com base na especificação do LNEC E 394 [21]. Assim, foi determinada a massa seca, a massa saturada e a massa hidrostática após a saturação dos provetes.

As observações da microestrutura das argamassas foram realizadas com recurso a um microscópio eletrônico de varredura de alta resolução (NanoSEM-FEI Nova 200). Para cada composição, foram preparados dois provetes cilíndricos com diâmetro e altura de aproximadamente $1 \mathrm{~cm}$.

O comportamento térmico foi avaliado com recurso a uma câmara climática, programada com uma lei de temperatura representativa da estação de verão no norte de Portugal. Os dados climáticos foram obtidos com recurso a uma estação meteorológica instalada no campus da Universidade do Minho, em Guimarães, Portugal. Para cada composição em teste, foi desenvolvida uma célula de teste em pequena escala, com recurso a um material isolante (poliestireno extrudido) com $3 \mathrm{~cm}$ de espessura e revestidas no interior com uma camada de argamassa de $1 \mathrm{~cm}$ de espessura. As células de teste de pequena escala possuem uma dimensão de $200 \times 200 \times 200 \mathrm{~mm}^{3}$. Em cada célula colocou-se um termopar no seu interior, na zona central, a uma altura de $10 \mathrm{~cm}$ da base da célula. Posteriormente, as células de teste colocaram-se dentro de uma câmara climática instrumentalizada com termopares, de forma a controlar a temperatura de ensaio. Cada termopar utilizado durante os ensaios térmicos conectou-se a um sistema de aquisição de dados de alta sensibilidade (Agilent 34970A), sendo o registo da temperatura no interior da câmara climática e das células de teste em escala reduzida avaliado a cada minuto. Os termopares utilizados foram do tipo K. Durante estes ensaios, o PCM atingiu a temperatura de transição de fase $\left(21^{\circ} \mathrm{C}\right.$ a $\left.24^{\circ} \mathrm{C}\right)$ armazenando e liberando energia. É importante notar que a composição das paredes das células de testes em pequena escala não é uma parede típica de um edifício, no entanto, a sua condutibilidade térmica $\left(\mathrm{U} \approx 0.89 \mathrm{~W} / \mathrm{m}^{2} \mathrm{~K}\right)$ é inferior ao limite máximo recomendado pela regulamentação portuguesa $\left(\mathrm{U} \approx 1.45 \mathrm{~W} / \mathrm{m}^{2} \mathrm{~K}\right)[22,23]$.

A Figura 1 apresenta a lei de temperatura utilizada nos ensaios térmicos, sendo possível observar uma temperatura mínima de $11^{\circ} \mathrm{C}$ e uma temperatura máxima de $44^{\circ} \mathrm{C}$, o que permite obter uma amplitude de temperatura de $33^{\circ} \mathrm{C}$. Cada ensaio térmico foi constituído por três ciclos, em que cada um teve uma duração de 24 horas.

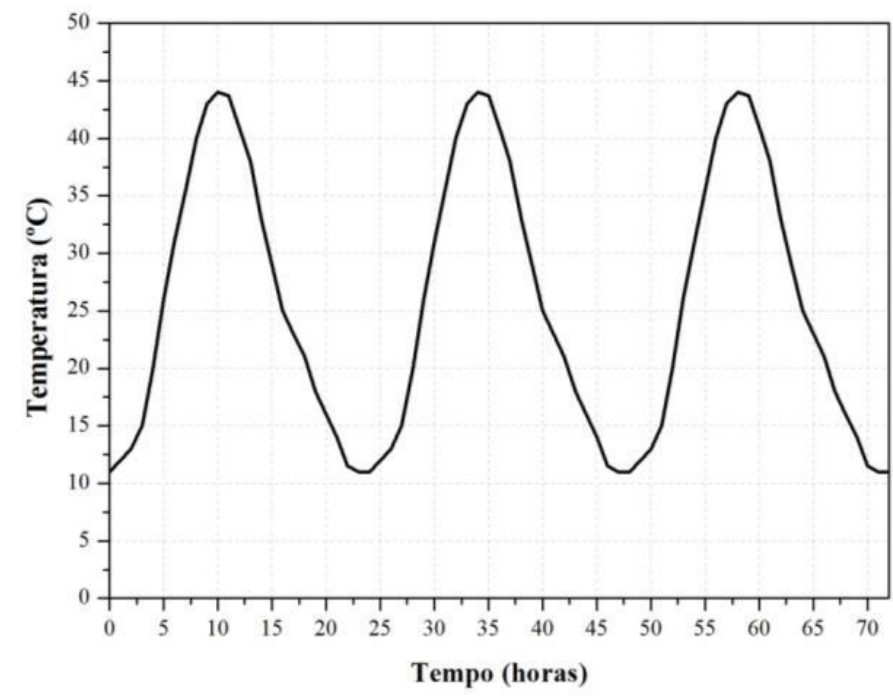

Figura 1: Lei de temperatura de verão.

\section{RESULTADOS E DISCUSSÕES}

\subsection{Trabalhabilidade}

A Figura 2 apresenta a dosagem de água adiconada às diferentes argamassas. Observou-se que a incorporação de $40 \%$ de PCM originou um aumento na quantidade de água superior a $25 \%$. Este comportamento pode ser justificado pela finura característica das microcápsulas de PCM. 


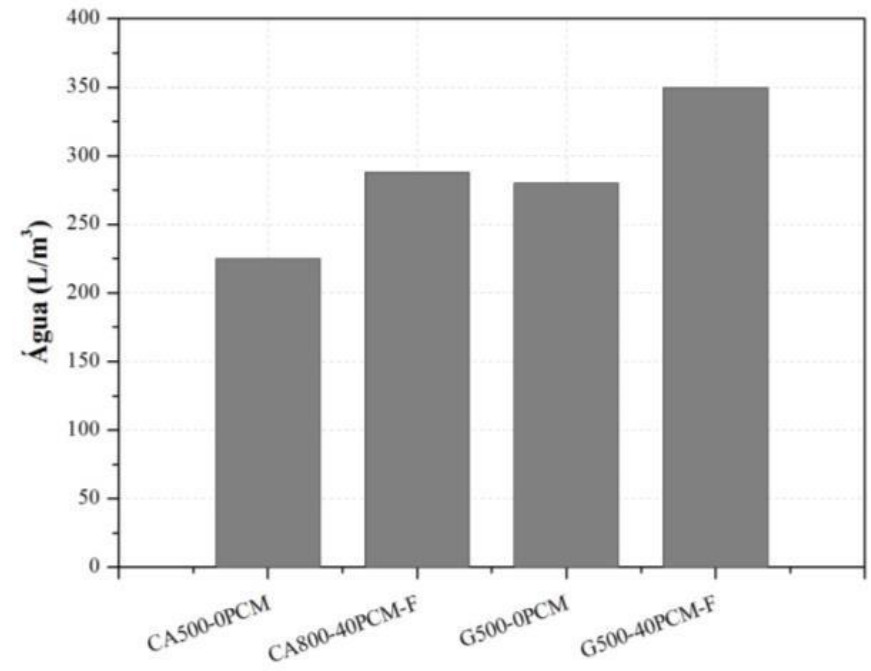

Figura 2: Dosagem de água das argamassas.

\subsection{Comportamento à flexão e compressão}

Tendo em conta a futura aplicação das argamassas na indústria da construção civil, as argamassas foram classificadas com base na suas resistências à compressão de acordo com a norma NP EN 998-1 (Tabela 2) [24]. A classificação mínima obtida foi de CSII, sendo esta uma das premissas deste trabalho.

Tabela 2: Classificação de argamassas baseada na resistência à compressão [24].

\begin{tabular}{l|l}
\hline CLASSE DE RESISTÊNCIA & VALORES \\
\hline CS I & 0.4 a $2.5 \mathrm{MPa}$ \\
\hline CS II & 1.5 a $5.0 \mathrm{MPa}$ \\
\hline CS III & 3.5 a $7.5 \mathrm{MPa}$ \\
\hline CS IV & $\geq 6 \mathrm{MPa}$ \\
\hline
\end{tabular}

A Tabela 3 apresenta o comportamento à flexão e compressão das argamassas desenvolvidas. Relativamente às argamassas de gesso, observou-se uma diminuição de $67 \%$ na resistência à flexão e uma diminuição de $78 \%$ na resistência à compressão, com a incorporação de $40 \%$ de microcápsulas PCM. Este comportamento pode ser justificado pelo aumento da razão água/ligante, que originou uma maior porosidade das argamassas. No entanto, nas argamassas à base de cal aérea, verificou-se um aumento de 149\% na resistência à flexão e um aumento de $82 \%$ na resistência à compressão, comparativamente à argamassa de referência (Tabela 3). O comportamento das argamassas à base de cal aérea pode ser justificado pela presença de uma maior dosagem de ligante e consequentemente, maior dosagem de superplastificante e menor dosagem de água. A utilização de uma maior dosagem de ligante nas argamassas à base de cal aérea, teve o objectivo de permitir obter a classificação mínima de CSII, uma vez que, a presença de dosagens de ligante inferiores a $800 \mathrm{~kg} / \mathrm{m}^{3}$ em argamassas com incorporação de $40 \%$ de microcápsulas de PCM originou uma classificação segundo a resistência à compressão de CSI.

Tabela 3: Resistências à flexão e à compressão, e classificação baseada na resistência à compressão das argamassas [24].

\begin{tabular}{l|l|l|l}
\hline COMPOSIÇÃO & $\begin{array}{l}\text { RESISTÊNCIA À } \\
\text { FLEXÃO }(\mathrm{MPa})\end{array}$ & $\begin{array}{l}\text { RESISTÊNCIA À } \\
\text { COMPRESSÃO } \\
(\mathrm{MPa})\end{array}$ & $\begin{array}{l}\text { CLASSIFICAÇÃO NP } \\
\text { EN 998-1:2010 }\end{array}$ \\
\hline CA500-0PCM & 0.65 & 1.90 & CS II \\
\hline CA800-40PCM-F & 1.62 & 3.46 & CS II \\
\hline G500-0PCM & 4.77 & 11.78 & CS IV \\
\hline
\end{tabular}




\begin{tabular}{l|l|l|l}
\hline G500-40PCM-F & 1.58 & 2.49 & CS II \\
\hline
\end{tabular}

\subsection{Absorção de água}

A absorção de água das argamassas desenvolvidas foi avaliada com base na absorção de água por capilaridade e na absorção de água por imersão. As diferentes argamassas foram classificadas com base no coeficiente de absorção capilar de acordo com a norma NP EN 998-1 (Tabela 4)[24].

Tabela 4: Classificação de argamassas baseada no coeficiente de absorção capilar [24].

\begin{tabular}{l|l}
\hline CLASSIFICAÇÃO & VALORES \\
\hline W0 & Não especificado \\
\hline W1 & $\leq 0.4 \mathrm{~kg} /\left(\mathrm{m}^{2} \cdot \mathrm{min}^{0.5}\right)$ \\
\hline W2 & $\leq 0.2 \mathrm{~kg} /\left(\mathrm{m}^{2} \cdot \mathrm{min}^{0.5}\right)$ \\
\hline
\end{tabular}

O coeficiente de absorção de água por capilaridade encontra-se relacionado com a velocidade da absorção de água e as dimensões dos poros. Assim, coeficientes mais elevados revelam a existência de uma maior quantidade de poros capilares, ou seja, poros de pequenas dimensões, e consequentemente um aumento na velocidade de absorção de água. Por sua vez, a absorção de água por imersão encontra-se relacionada com a quantidade de poros de grandes dimensões.

A Tabela 5 revela que a incorporação de $40 \%$ de microcápsulas de PCM originou um aumento no coeficiente de absorção capilar em cerca de 5\%. Observou-se ainda um aumento na absorção de água por imersão superior a $8 \%$. Este comportamento pode ser justificado pelo aumento da quantidade de água utilizada na produção das argamassas com incorporação de PCM, originando argamassas mais porosas.

Tabela 5: Absorção de água e classificação baseada no coeficiente de absorção capilar das argamassas [24].

\begin{tabular}{l|l|l|l}
\hline COMPOSIÇÃO & $\begin{array}{l}\text { COEFICIENTE DE AB- } \\
\text { SORÇÃO DE ÁGUA POR } \\
\text { CAPILARIDADE } \\
\left(\mathbf{k g} /\left(\mathbf{m}^{2} \cdot \mathbf{m i n}^{0.5}\right)\right.\end{array}$ & $\begin{array}{l}\text { ABSORÇÃO DE ÁGUA } \\
\text { POR IMERSÃO }(\%)\end{array}$ & $\begin{array}{l}\text { CLASSIFICAÇÃO } \\
\text { NP EN 998-1:2010 }\end{array}$ \\
\hline CA500-0PCM & 0.22 & 13.8 & W1 \\
\hline CA800-40PCM-F & 0.23 & 18.7 & W1 \\
\hline G500-0PCM & 0.94 & 21.0 & W0 \\
\hline G500-40PCM-F & 0.96 & 22.6 & W0 \\
\hline
\end{tabular}

A Tabela 5 apresenta ainda a classificação das argamassas com base no coeficiente de absorção de água por capilaridade, de acordo com a norma NP EN 998-1 [24]. Foi possível observar que para cada ligante a classe de absorção de água capilar mantém-se constante. As argamassas à base de gesso apresentam uma classificação de W0 e as argamassas à base de cal aérea uma classificação de W1. Assim, foi possível concluir que as argamassas de gesso apresentaram maiores coeficientes de absorção capilar, comparativamente com as argamassas à base de cal aérea. Estes resultados devem-se à maior porosidade das argamassas de gesso. Por outro lado, este comportamento encontra-se ainda relacionado com o comportamento à flexão e compressão, uma vez que o aumento da porosidade das argamassas originou uma maior perda das características mecânicas. No entanto, a maior porosidade das argamassas com incorporação de PCM origina uma maior permeabilidade ao vapor de água, tal como requerido nas argamassas para a reabilitação de edifícios.

\subsection{Microestrutura}

De forma a avaliar a existência de possíveis incompatibilidades entre os diferentes materiais constituintes das argamassas, foram realizados vários ensaios com recurso ao microscópio eletrônico. A Figura 3 apresenta a microestrutura das argamassas desenvolvidas, sendo possível observar que as microcápsulas de PCM apresentam uma distribuição homogênea, sem qualquer sinal de aglomeração. Observou-se também uma boa compatibilidade entre os diferentes materiais constituintes das argamassas (microcápsulas de PCM, ligante e 
agregado), evidenciada pela ausência de fissuras na zona de ligação entre os mesmos. As microcápasulas de PCM mostraram ainda que resistem adequadamente aos processos de mistura, aplicação e cura da argamassa, uma vez que não apresentaram sinais de ruptura ou danos.

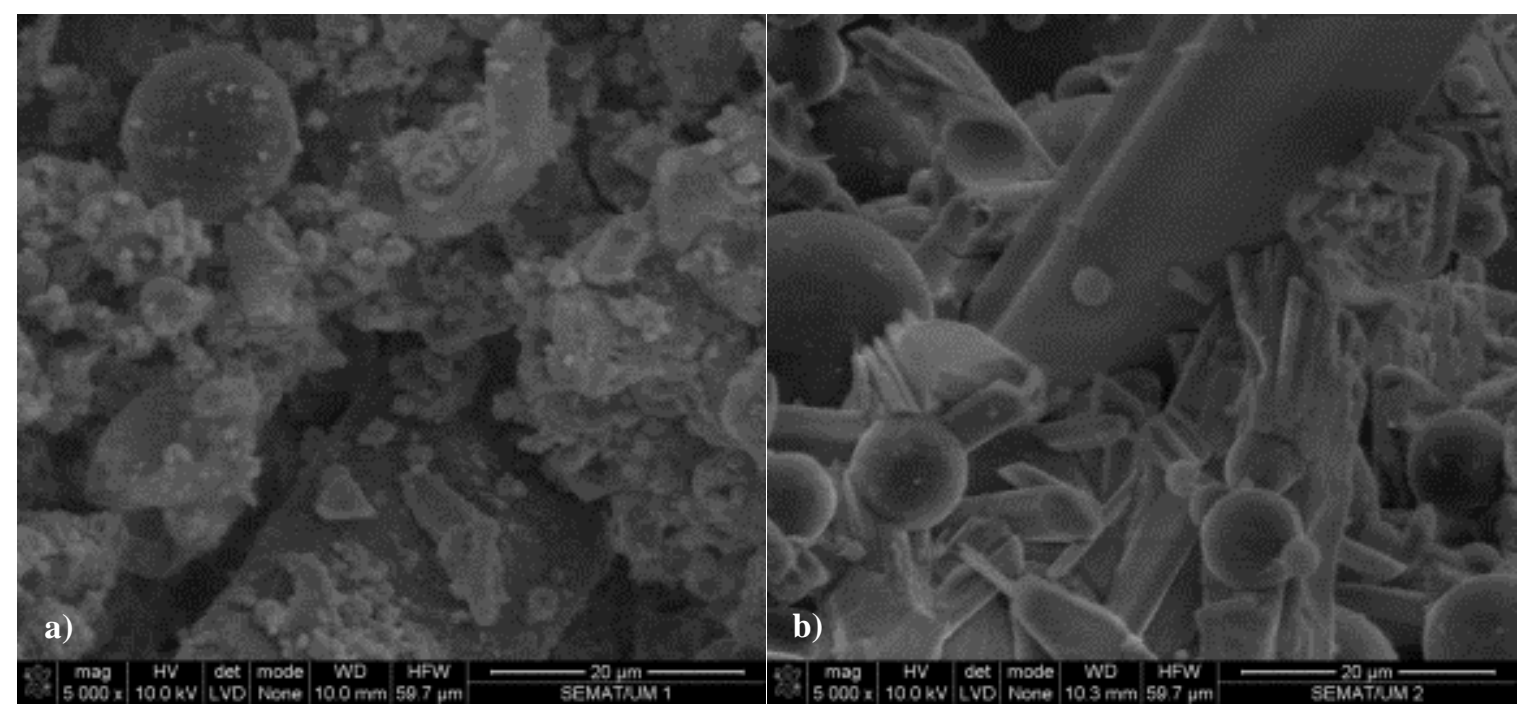

Figura 3: Microestrutura das argamassas, ampliação 5000x: a) Argamassa à base de cal aérea com incorporação de 40\% de PCM (CA800-40PCM-F); b) Argamassa à base de gesso com incorporação de 40\% de PCM (G500-40PCM-F).

Estes ensaios permitiram ainda a avaliação do tamanho e distribuição dos poros nas diferentes argamassas (Figuras 4 e 5). Observou-se um aumento da microporosidade e a presença de microporos de maiores dimensões nas argamassas com incorporação de PCM comparativamente com as argamassas de referência. Verificou-se ainda que a matriz das argamassas de referência apresenta uma estrutura mais compacta. A presença de uma maior quantidade de microporos nas argamassas com incorporação de PCM, pode ser explicada pela maior quantidade de água utilizada para a produção das mesmas, devido às reduzidas dimensões das partículas de PCM.

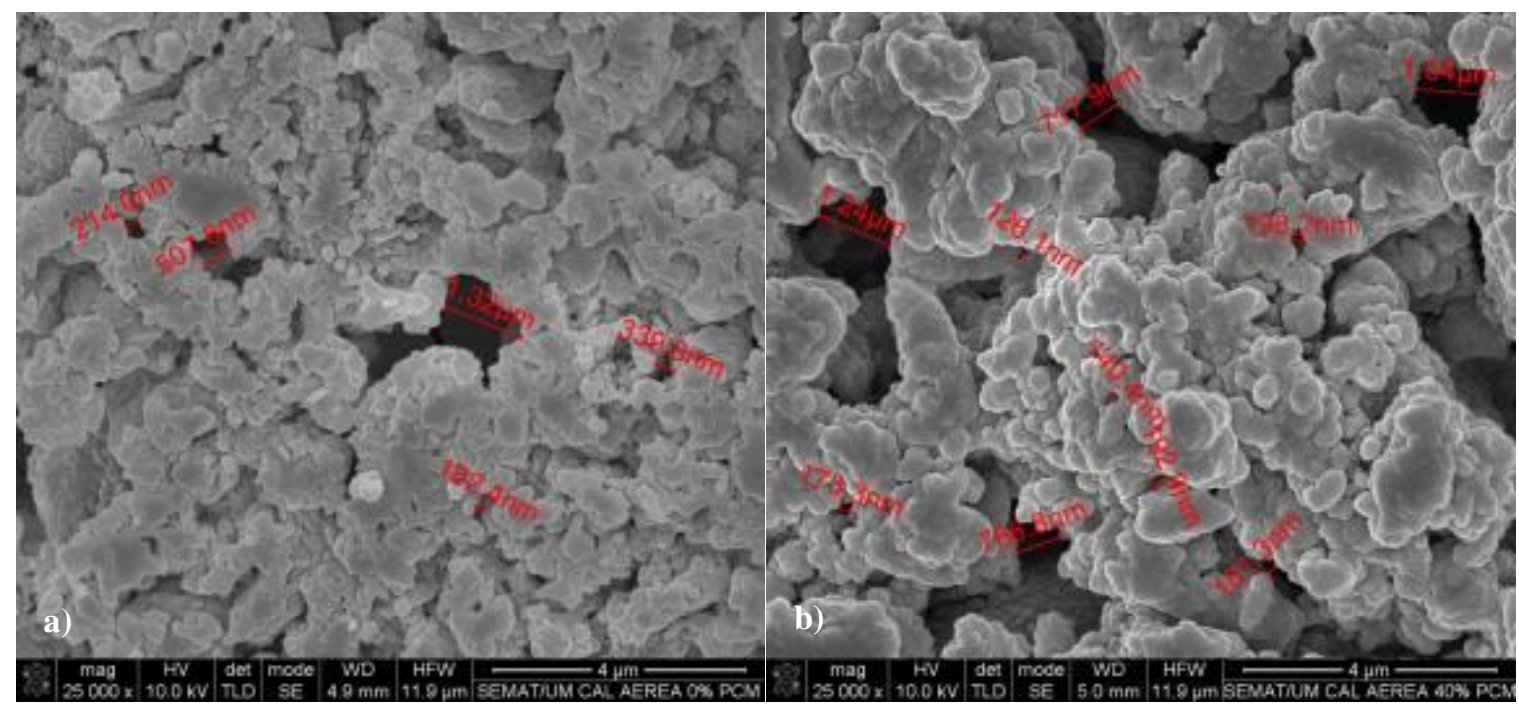

Figura 4: Microestrutura das argamassas à base de cal aérea, ampliação 25000x: a) Argamassa sem incorporação de PCM (CA500-0PCM ); b) Argamassa com incorporação de 40\% de PCM (CA800-40PCM-F).

\subsection{Comportamento térmico}

A temperatura externa influencia significativamente o comportamento do PCM. Assim, este material tem grande influência em áreas onde inverno e verão são mais rigorosos [25, 26, 27]. A Figura 6 apresenta o 
comportamento das argamassas na estação de verão, tendo sendo possível verificar o efeito positivo da incorporação de PCM. Em todas as composições com incorporação de PCM (Figura 6), observou-se que quando a temperatura atinge a faixa entre $20^{\circ} \mathrm{C}$ e $25^{\circ} \mathrm{C}$, ocorre a mudança de fase do PCM e o comportamento térmico das argamassas PCM começa a evoluir de forma diferente, comparativamente com a curva de temperatura das argamassas de referência. Na situação de arrefecimento, ou seja, quando a temperatura excede $25^{\circ} \mathrm{C}$, as argamassas com PCM apresentam uma taxa de arrefecimento mais elevada e uma temperatura máxima mais baixa. O mesmo foi verificado para a situação de aquecimento, ou seja, quando a temperatura é inferior a $20^{\circ} \mathrm{C}$, verificando-se um aumento da temperatura mínima para as argamassas com PCM. Quando a temperatura se encontra perto da zona de conforto térmico $\left(20^{\circ} \mathrm{C}\right.$ a $\left.25^{\circ} \mathrm{C}\right)$, as células com e sem incorporação de PCM exibem valores de temperatura semelhantes. O efeito do armazenamento e libertação de calor é notório apenas quando a temperatura diverge da zona de conforto.

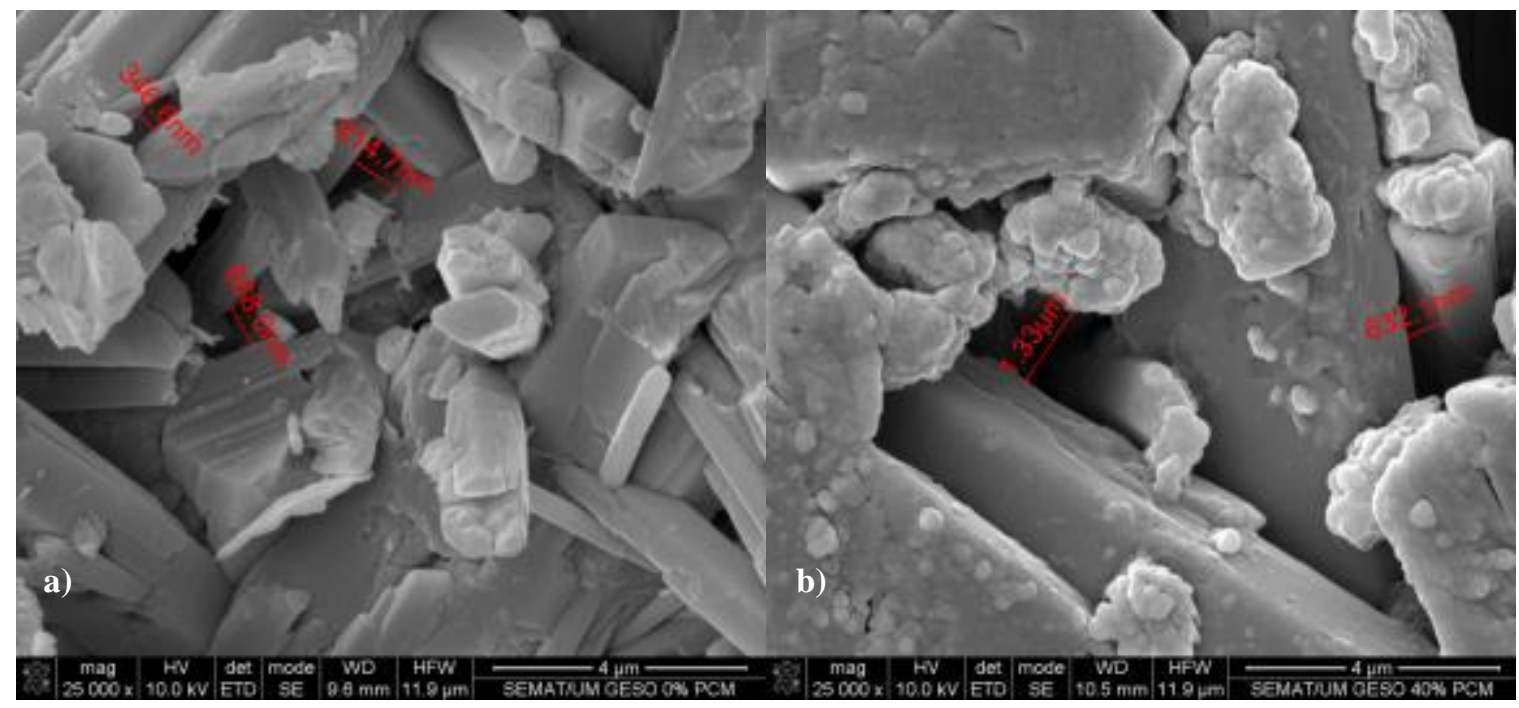

Figura 5: Microestrutura das argamassas à base de gesso, ampliação 25000x: a) Argamassa sem incorporação de PCM (G500-0PCM ); b) Argamassa com incorporação de 40\% de PCM (G500-40PCM-F).
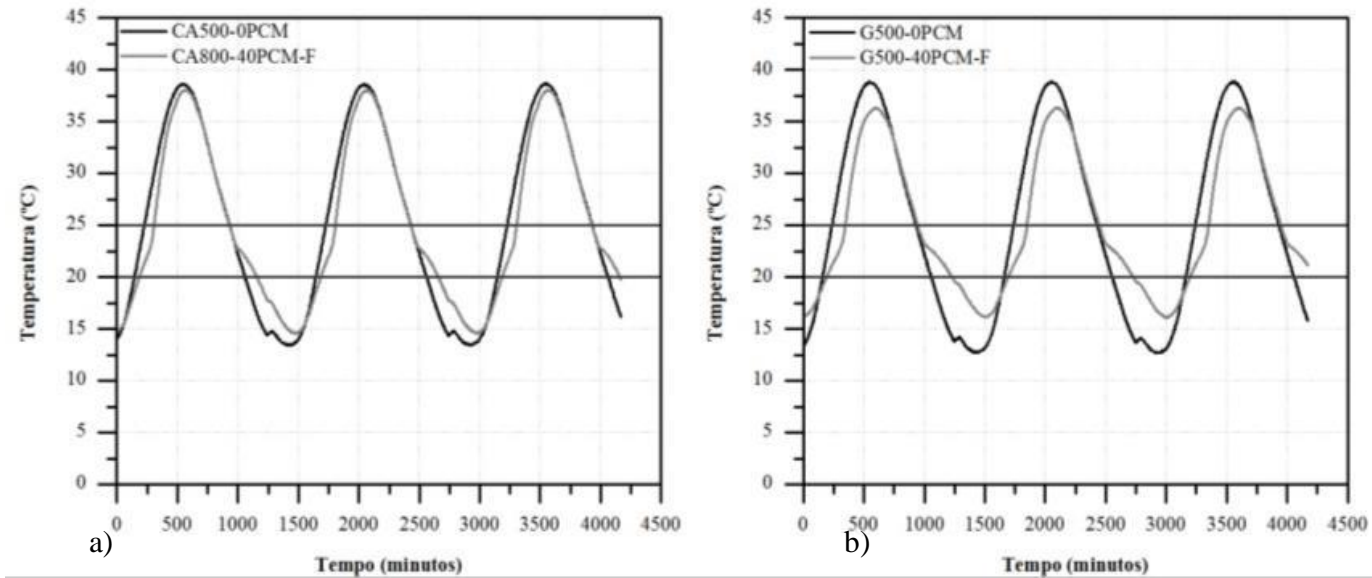

Figura 6: Comportamento térmico das argamassas na estação de verão: a) Argamassas à base de cal aérea; b) Argamassas à base de gesso.

É importante notar que em todas as composições testadas foi verificado o efeito positivo do PCM. As células revestidas com as argamassas com incorporação de PCM não atingiram temperaturas máximas tão elevadas, nem temperaturas mínimas tão baixas como as células de referência ( $0 \%$ PCM). Este comportamento pode ser comprovado pela diminuição da amplitude diária da temperatura no interior das células de testes em escala reduzida (Tabela 6). Observou-se uma diferença entre as temperaturas mínimas e máximas de cerca de $3^{\circ} \mathrm{C}$ e $6^{\circ} \mathrm{C}$, respectivamente, o que é consistente com outros estudos [22, 28]. 
Com base nas curvas de temperatura foi ainda possível observar uma diminuição da temperatura máxima superior a 3\% na situação de arrefecimento e um aumento da temperatura mínima superior a $15 \%$ na situação de aquecimento (Figura 7). Este comportamento significa um tempo de operação de sistemas de climatização mais curto em espaços revestidos com argamassas com incorporação de PCM, traduzindo-se numa forma de economizar energia.

Tabela 6: Gama de temperaturas e amplitude térmica.

\begin{tabular}{l|l|l}
\hline COMPOSIÇÃO & GAMA DE TEMPERATURA (C) & AMPLITUDE TÉRMICA \\
\hline CA500-0PCM & $13-39$ & 26 \\
\hline CA800-40PCM-F & $15-38$ & 23 \\
\hline G500-0PCM & $13-39$ & 26 \\
\hline G500-40PCM-F & $16-36$ & 20 \\
\hline
\end{tabular}
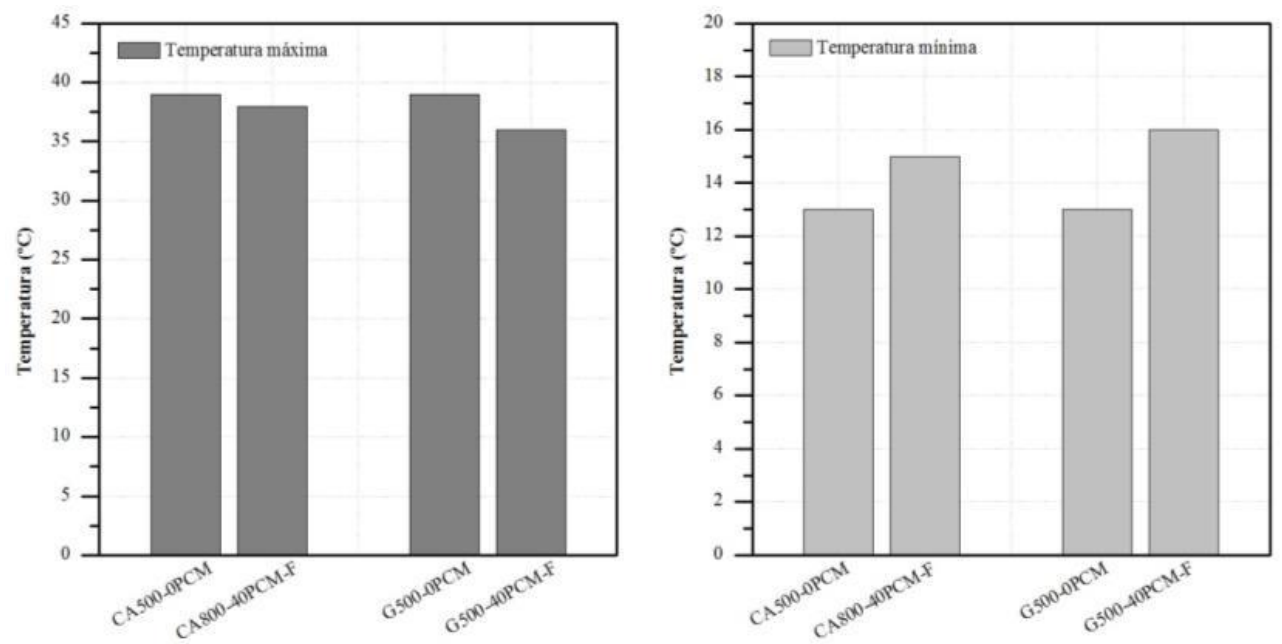

Figura 7: Temperaturas máxima e mínima.

Durante estes testes foram também observados desfasamentos temporais nas temperaturas máxima e mínima de 30 minutos durante a situação de arrefecimento e 60 minutos durante a situação de aquecimento, nas argamassas à base de cal aérea. Relativamente às argamassas à base de gesso, verificaram-se desfasamentos temporais de 55 minutos durante a situação de arrefecimento e de 85 minutos durante a situação de aquecimento. Sabe-se que, actualmente, a maior parte do consumo de energia electrica nos edifícios residenciais encontra-se associado ao aquecimento e arrefecimento dos mesmos. Existe ainda uma taxação da energia diferenciada durante o dia e a noite, assim a deslocalização dos consumos elevados para períodos de baixa procura energética, apresenta-se como uma vantagem econômica.

Para melhor compreender a influência do PCM no comportamento térmico das argamassas, foi utilizada uma abordagem simplificada com base nas curvas de temperatura, de forma a obter as necessidades de aquecimento e arrefecimento. As necessidades de aquecimento e arrefecimento foram calculadas integrando as curvas tempo-temperatura (Figura 6). O valor global resultante da integração das curvas tempotemperatura foi transformado no consumo de energia utilizando a equação 1 [22]:

$$
C_{N}=\int_{t i}^{t f} \rho_{C V} T d t / \Delta T
$$

Onde:

$C_{N}-$ Necessidades de aquecimento ou arrefecimento $(\mathrm{J} / \mathrm{m} 3)$

$t_{i}$ - Instante inicial da curva tempo-temperatura (h); 
$t_{f}-$ Instante final da curva tempo-temperatura $(\mathrm{h})$;

$\rho_{C V}$-Capacidade calorífica volumétrica do ar $\left(\mathrm{J} / \mathrm{m}^{3} \mathrm{~K}\right)$;

T - Valor resultante da integração da curva tempo-temperatura (K.h);

$\Delta \mathrm{T}$ - Diferença entre o tempo final e inicial (h).

A Tabela 7 apresenta as necessidades de aquecimento e arrefecimento. Observou-se que a incorporação de PCM originou uma diminuição das necessidades de aquecimento e arrefecimento superior a $11 \%$, o que mais uma vez demonstra o efeito benéfico da incorporação de PCM em argamassas de revestimento interior. Relativamente às necessidades de climatização totais, verificou-se que a incorporação de microcápsulas de PCM originou uma diminuição de cerca de $11 \%$ nas argamassas à base de cal aérea e de cerca de $21 \%$ nas argamassas à base de gesso. Assim, foi possível concluir que as argamassas à base de gesso apresentaram uma melhor regulação térmica, com base na maior redução da temperatura máxima, maior aumento da temperatura mínima, maior desfasamento temporal e maior diminuição das necessidades de aquecimento e arrefecimento. Esta situação pode ser justificada pela presença de uma maior quantidade de microporos, demonstrada pelo maior coeficiente de absorção de água por capilaridade, maior quantidade de água absorvida por imersão e microestrutura. Assim, pode concluir-se que a maior presença de poros melhora o efeito da regulação da temperatura, uma vez que existem mais microcápsulas de PCM em contacto com o ambiente.

Tabela 7: Necessidades de aquecimento e arrefecimento $\left(\mathrm{J} / \mathrm{m}^{3}\right)$.

\begin{tabular}{l|l|l|l}
\hline COMPOSIÇÃo & $\begin{array}{l}\text { NECESSIDADES DE } \\
\text { ARREFECIMENTO }\end{array}$ & $\begin{array}{l}\text { NECESSIDADES DE } \\
\text { AQUECIMENTO }\end{array}$ & $\begin{array}{l}\text { NECESSIDADES DE } \\
\text { CLIMATIZAÇÃO }\end{array}$ \\
\hline CA500-0PCM & 269086 & 253529 & 522615 \\
\hline CA800-40PCM-F & 238032 & 227959 & 465991 \\
\hline G500-0PCM & 269216 & 253095 & 522311 \\
\hline G500-40PCM-F & 217102 & 196061 & 413163 \\
\hline
\end{tabular}

\section{CONCLUSÃO}

Neste trabalho foi realizada uma campanha experimental com o objetivo de comparar as principais propriedades físicas, mecânicas e térmicas de argamassas à base de cal e de gesso com incorporação de PCM, para utilização em operações de reabilitação. Com base nos resultados obtidos, pode concluir-se que a incorporação de microcápsulas de PCM nas argamassas originou alterações significativas nas suas propriedades no estado fresco e endurecido.

Relativamente à dosagem de água das argamassas, verificou-se que a incorporação de microcápsulas de PCM provocou um aumento na quantidade de água adicionada às mesmas, de forma a permitir obter uma trabalhabilidade adequada. Este aumento na quantidade de água encontra-se relacionado com a finura característica das microcápsulas de PCM, exigindo uma maior quantidade de água para obter uma trabalhabilidade similar. Por outro lado, a incorporação de microcápsulas de PCM em argamassas provocou um aumento na absorção de água, revelando uma maior porosidade das argamassas. No que diz respeito ao estudo das resistências mecânicas observou-se uma diminuição das mesmas com a incorporação de PCM, consequência da maior porosidade. No entanto, foi possível manter sempre uma classe de resistência que garante um bom comportamento.

No que confere às observações microscópicas, verificou-se a existência de uma boa interação entre todos os constituintes das argamassas, evidenciada pela ausência de fissuras. Observou-se também uma distribuição uniforme das microcápsulas de PCM e restantes constituintes das argamassas.

De acordo com o comportamento térmico, a utilização de argamassas com incorporação de PCM provou ser uma estratégia eficiente para o desenvolvimento de edifícios sustentáveis, devido à redução de temperaturas extremas, diminuição das necessidades de aquecimento e arrefecimento, e aumento do desfasamento das temperaturas extremas. Assim, é possível concluir que a utilização de argamassas com incorporação de 
PCM permite reduzir os consumos energéticos, a exploração de combustíveis fósseis e o impacto ambiental associado à utilização de equipamentos de climatização.

\section{AGRADECIMENTOS}

Os autores desejam expressar os seus agradecimentos à Fundação para a Ciência e Tecnologia (FCT) pelo financiamento deste trabalho no âmbito da bolsa de doutoramento SFRH/BD/95611/2013.

\section{BIBLIOGRAFIA}

[1] HAURIE, L., LACASTA, A., CIUDAD, A., et al., "Addition of flame retardants in epoxy mortars: Thermal and mechanical characterization", Construction and Building Materials, v. 42, pp. 266-270, May 2013.

[2] CHEN, J., KOU, S., POON, C., "Photocatalytic cement-based materials: Comparison of nitrogen oxides and toluene removal potentials and evaluation of self-cleaning performance",Building and Environment, v. 46, pp. 1827-1833, Sep. 2011.

[3] HUSKEN, G., HUNGER, M., BROUWERS H., "Experimental study of photocatalytic concrete products for air purification", Building and Environment, v. 44, pp. 2463-2474, Dec. 2009.

[4] STRINI, A., CASSESE, S., SCHIAVI, L., "Measurement of benzene, toluene, ethylbenzene and o-xylene gas phase photodegradation by titanium dioxide dispersed in cementitious materials using a mixed flow reactor", Applied Catalysis B: Environmental, v. 61, pp. 90-99, Oct. 2005.

[5] CUNHA, S., AGUIAR, J. B, FERREIRA, V. M., et al., "Mortars Based in different binders with incorporation of phase change materials: Physical and mechanical properties", European Journal of Environmental and Civil Engineering, v. 19, pp 1216-1233, 2015.

[6] DARKWA, K., O'CALLAGHAN, P., TETLOW, D., "Phase-change drywalls in a passive-solar building", Applied Energy, v. 83, pp. 425-435, May 2006.

[7] ATHIENITIS, A., LIU, C., HAWES, D., et al., "Investigation of the Thermal Performance of a Passive Solar Test-Room with Wall Latent Heat Storage", Building and Environment, v. 32, pp. 405-410, Sep. 1997.

[8] SHILEI, L., NENG, Z., GUOHUI, F., "Impact of Phase Change Wall Room on Indoor Thermal Environment in winter", Energy and Buildings, v. 38, pp. 18-24, Jan. 2006.

[9] BRÁS, A., ROCHA, A., FAUSTINO, P., "Integrated approach for school buildings rehabilitation in a Portuguese city and analysis of suitable third party financing solutions in EU", Journal of Building Engineering, v. 3, pp. 79-93, Sep. 2015.

[10] BILGEN, S., "Structure and environmental impact of global energy consumption", Renewable and Sustainable Energy Reviews, v. 38, pp. 890-902, Oct. 2014.

[11] MUNARIM, U., GHISI, E., "Environmental feasibility of heritage buildings rehabilitation". Renewable and Sustainable Energy Reviews, v. 58, pp. 235-49, May 2016.

[12] SCHOSSIG, P., HENNING, H., GSCHWANDER, S., et al., "Micro-encapsulated Phase Change Materials Integrated in to Construction Materials", Solar Energy Materials \& Solar Cells, v. 89, pp. 297-306, Nov. 2005.

[13] AHMAD, M., BONTEMPS, A., SALLÉE, H., et al., "Thermal Testing and Numerical Simulation of a Prototype Cell Using Light Wallboards Coupling Vacuum Isolation Panels and Phase Change Material", Energy and Buildings, v. 38, pp. 673-681, Jun. 2006.

[14] CABEZA, L., CASTELL, A., BARRENECHE, C., et al., "Materials used as PCM in thermal energy storage in buildings: A review", Renewable and Sustainable Energy Reviews, v. 15, pp. 1675-1695, Apr. 2011.

[15] LIN, K., ZHANG, Y., XU, X., et al., "Experimental Study of Under-Floor Electric Heating System with Shape-Stabilized PCM Plates", Energy and Buildings, v. 37, pp. 215-220, Mar. 2005.

[16] ENTROP, A., BROUWERS, H., REINDERS, A., "Experimental research on the use of microencapsulated Phase Change Materials to store solar energy in concrete floors and to save energy in Dutch houses", Solar Energy, v. 85, pp. 1007-1020, May. 2011.

[17] JIN, X., ZHANG, X., "Thermal analysis of a double layer phase change material floor", Applied Thermal Engineering, v. 31, pp. 1576-81, Jul. 2011. 
[18] EUROPEAN COMMITTEE FOR STANDARDIZATION (CEN), EN 1015-11, "Methods of test for masonry - Part 11: Determination of flexural and compressive strength of hardened mortar", 1999.

[19] EUROPEAN COMMITTEE FOR STANDARDIZATION (CEN), EN 1015-3, "Methods of test for mortar for masonry - Part 3: Determination of consistence of fresh mortar (by flow table)", 1999.

[20] EUROPEAN COMMITTEE FOR STANDARDIZATION (CEN), EN 1015-18, "Methods of test for masonry - Part 18: Determination of water absorption coefficient due to capillary action of hardened mortar", 2002.

[21] LABORATÓRIO NACIONAL DE ENGENHARIA CIVIL (LNEC), Especificação E 394, "Betões Determinação da absorção de água por imersão", 1993.

[22] RCCTE, Regulação das Características do Comportamento Térmico de Edifícios, 2006.

[23] KHERADMAND, M., AZENHA, M., AGUIAR, J. L. B., et al.,"Experimental and numerical studies of hybrid PCM embedded in plastering mortar for enhanced thermal behaviour of buildings", Energy, v. 94, pp. 250-61, Jan. 2016.

[24] INSTITUTO PORTUGUÊS DA QUALIDADE (IPQ), NP EN 998-1, "Especificações de argamassas para alvenarias - Parte 1: Argamassas para rebocos interiores e exteriores”, 2010.

[25] KHUDHAIR, A., FARID, M., “A review on energy conservation in building applications with thermal storage by latent heat using phase change materials", Energy Conversion and Management,v. 45, pp. 263275, Jan. 2004.

[26] LI, J., XUE, P., HE, H., et al., "Preparation and application effects of a novel form-stable phase change material as the thermal storage layer of an electric floor heating system", Energy and Buildings, v. 41, pp. 871-880, Aug. 2009.

[27] HERNÁNDEZ, V., MORILLÓN, D., BEST, R., et al., "Experimental and numerical model of wall like solar heat discharge passive system”, Applied Thermal Engineering, v. 26, pp. 2464-2469, Dec. 2006.

[28] SÁ, A. V., AZENHA, M., SOUSA, H., et al., "Thermal enhancement of plastering mortars with Phase Change Materials: Experimental and numerical approach”, Energy and Buildings, v. 49, pp.16-27, Jun. 2012. 